\title{
The effect of ketamine as an additive in epidural block on the intractable herpetic neuralgia
}

- a case report-

\author{
Jin Young Lee, Woo Seog Sim, Kyung Mi Kim, Min Seok Oh, and Ji Eun Lee \\ Department of Anesthesiology and Pain Medicine, Samsung Medical Center, Sungkyunkwan University School of Medicine, Seoul, Korea
}

Ketamine has been shown to have analgesic effect by blocking N-methyl-D-aspartate receptor, thus preventing and reducing central sensitization caused by peripheral nociceptive stimulation. However, due to lack of knowledge about its safety and toxicity in the central nervous system, either epidural or intrathecal injection of ketamine still remains controversial. Here, we describe a case report of satisfactory pain relief after the addition of ketamine in epidural injection in a patient with severe herpes zoster pain that was refractory to conventional medication, intravenous opioids and continuous epidural block. This case indicates the viability of epidural ketamine injection in patients with intractable herpetic neuralgia. (Korean J Anesthesiol 2014; 66: 64-66)

Key Words: Epidural analgesia, Herpes zoster, Ketamine.

Painful zoster neuropathy is a significant source of morbidity following reactivation of dormant varicella zoster virus in the dorsal root ganglia. Varicella-zoster viral particles travel down the neuronal axon to the skin and produce painful, vesicular cutaneous lesions on the affected dermatome. Early zoster diagnosis and adequate pain control are crucial to minimize central neural sensitization. N-methyl-D-aspartate (NMDA) receptors are an important component of the pain pathway where central sensitization is involved. Ketamine is an NMDA receptor antagonist, which exerts a strong analgesic effect by inhibiting the wind-up phenomenon of dorsal horn nociceptive neurons. In a number of studies, epidural ketamine produces prolonged analgesia in acute pain control, possibly from interaction with antinociceptive spinal receptors [1-5]. In this report, we tried a single ketamine injection by the lumbar epidural route for a patient with severe pain following zoster, with excellent results. Epidural ketamine injection can thus be a feasible approach for patients with intractable herpetic neuralgia.

\section{Case Report}

A 35-year-old, $162 \mathrm{~cm}, 61 \mathrm{~kg}$ female patient was referred to our pain clinic due to severe painful rashes in the right lower extremity (L3 to L5 dermatome). Her past medical history includ-

Received: October 23, 2012. Revised: November 28, 2012. Accepted: December 10, 2012.

Corresponding author: Woo Seog Sim, M.D., Ph.D., Department Anesthesiology and Pain Medicine, Samsung Medical Center, 81, Il-won-ro, Gangnam-gu, Seoul 135-710, Korea. Tel: 82-2-3410-0356, Fax: 82-2-3410-6626, E-mail: anesthe@skku.edu

(c) This is an open-access article distributed under the terms of the Creative Commons Attribution Non-Commercial License (http:// creativecommons.org/licenses/by-nc/3.0/), which permits unrestricted non-commercial use, distribution, and reproduction in any medium, provided the original work is properly cited. 
ed acute myeloid leukemia for 15 months and peripheral blood stem cell transplantation had been carried out eleven months previously. The rash had developed 25 days ago and clinical evaluation confirmed acute herpes zoster neuropathy. The viral skin lesions resolved successfully with intravenous acyclovir during the acute phase. However, the leg pain remained severe and significantly increased despite treatment with pregabalin, opioids, tricyclic antidepressants, corticosteroids, benzodiazepines and non-steroidal anti-inflammatory drugs. She suffered from continuous burning pain ( 8 points on verbal rating scale [VRS], $0=$ no pain, 10 = worst pain imaginable) with intermittent electrical shock-like painful sensation (10 VRS) occurring approximately every $30 \mathrm{~min}$, each lasting several seconds. The affected area was sensitive to touch and she felt numbness and tingling. She also reported intermittent discoloration on her affected dermatomes from red to dark red. She had been treated with pregabalin 450 $\mathrm{mg}$, oxycodone $320 \mathrm{mg}$, tramadol $300 \mathrm{mg}$, fentanyl patch $100 \mu \mathrm{g}$, amitriptyline $10 \mathrm{mg}$, fluoxetine $20 \mathrm{mg}$ in a day and morphine intravenous patient-controlled analgesia (PCA) with a basal rate of $4 \mathrm{mg} / \mathrm{h}$ and a bolus dose of $2 \mathrm{mg}$ to control the pain. Despite escalating doses of medication and intravenous PCA infusion, her pain remained at 8 VRS. We considered lumbar epidural PCA infusion for pain relief. With patient approval, an epidural catheter was inserted into the L2-3 interlaminar epidural space and was confirmed on fluoroscopy. A sensory block below the L3 dermatome was established. However, continuous epidural PCA infusion of $0.375 \%$ ropivacaine and morphine sulfate 0.4 $\mathrm{mg} / \mathrm{h}$ did not alleviate pain sufficiently (7 VRS). Approximately one week after epidural PCA administration, we tried singleshot ketamine (Ketomine ${ }^{\circledR}$, Dai Han Pharmaceutical, Seoul, Korea) $5 \mathrm{mg}$, which was diluted in normal saline to $3 \mathrm{ml}$, through the lumbar epidural catheter. Within a few hours, she reported substantial pain relief without significant adverse effect (5 VRS). After three days, she received a second single-shot of ketamine 5 $\mathrm{mg}$ via the epidural route. The pain area was gradually reduced in size and allodynia was improved (3 VRS). Epidurally administered ketamine, in addition to ropivacaine and morphine, provided sufficient and prolonged analgesia. Five days later, the epidural PCA could be stopped and she was discharged in a stable condition with a VRS below 3 . She has been followed in a VRS 2 to 3 by our pain clinic for the past four months and is undergoing tapering of her medications including pregabalin 75 $\mathrm{mg}$ and oxycodone $10 \mathrm{mg}$ a day without further nerve block.

\section{Discussion}

Postherpetic neuralgia is typically defined as pain persisting at least three months after herpetic rash onset [6]. Some patients experience this pain as a continuation of that previously experienced with the acute herpes zoster eruption, which has been described as a burning or stabbing sensation, itching or tingling. There is some evidence for loss of dorsal root ganglion cells and axons in the affected nerve root and peripheral nerve due to herpes zoster, which makes postherpetic neuralgia a neuropathic pain syndrome. Various conditions such as malignancy, immune deficiencies, psychological conditions and autoimmune diseases may trigger the activation of varicella zoster virus. Following organ transplantation, varicella zoster virus infection is the most common viral disease, with a reported incidence rate ranging between 17 and 50\%, primarily within the first nine months after transplantation [7]. Previous studies suggest that older age, female sex, presence of prodrome, greater acute pain severity and greater rash severity are risk factors for prolonged zoster pain [8]. There are various protocols for the pain management of herpetic neuralgia. The main concerns are adequate pain control and minimization of central neural sensitization. Commonly employed therapies are oral anticonvulsants, tricyclic antidepressants, opioids, topical agents and more invasive options, including local infiltration, sympathetic, epidural and intrathecal injections.

Ketamine has multiple pharmacological effects due to interaction with many channels and receptors [9]. For many decades its primary use has been as a pediatric sedative or anesthetic agent. In the past 15 years, ketamine has drawn interest for its antihyperalgesic or antiallodynic effect, which acts to influence synapse formation and neuroplasticity, resulting in the prevention and reduction central neural sensitization caused by peripheral nociceptive stimulation [10]. Clinically, ketamine can be administered via intravenous, intramuscular, epidural, intrathecal, rectal, subcutaneous, transdermal, topical, oral, intranasal, transmucosal and sublingual routes. Epidural ketamine provides prolonged analgesia when administered alone or added to local anesthetics [1-5]. Epidural injection has an additional benefit in that inadvertent intravascular administration will not result in cardiovascular side effects. Intrathecal ketamine 3 to $10 \mathrm{mg} / \mathrm{kg}$ showed dose-dependent antihyperalgesic effects in neonatal rats [11]. The majority of ketamine research has been carried out in animals or in vitro due to the ethical impossibility of conducting human studies. Accordingly, the safety of epidural or intrathecal ketamine in human has been questioned. There have been reports of adverse effects of epidural or intrathecal injection of ketamine. Schnabel et al. [4] reported that epidural ketamine caused sedation, hallucination or temporary nystagmus in some cases, but there were no major neurological complications in 125 children. Intrathecal ketamine is potentially neurotoxic even at lower dose, perhaps related to higher local concentrations in the central nervous system (CNS), probably by inducing neuroapoptosis or neuronal cell death in new born animal models [11]. Suspected mechanisms are excitotoxicity, loss of the trophic role of NMDA receptors and metabolic alterations in the CNS levels 
of glutathione, glutamine and glutamate [12]. Malinovsky et al. [13] blamed the preservative benzethonium chloride or chlorobutanol in ketamine formulation as a possible cause of neurotoxicity, but other research showed that even a preservative-free ketamine formulation can be neurotoxic [12]. In our case, we used ketamine with preservative benzethonium chloride due to difficulty in obtaining preservative-free ketamine. The optimal ketamine dose and infusion duration is unclear, especially for immunocompetent patients. Post-mortem CNS histopathological spinal cord changes in a terminal cancer patient after continuous intrathecal ketamine infusion at a rate of $5 \mathrm{mg} /$ day for three weeks has been reported [14]. In that case, several complicating conditions, including long term intrathecal ketamine treatment, previous radiotherapy and chemotherapy, might have been related to this spinal cord degeneration. A meta-analysis for efficacy and side effects of epidural ketamine found no major neurological and systemic complications at $0.25-0.50 \mathrm{mg} / \mathrm{kg}$ ketamine dose in healthy children [4]. So, we recommend small doses or a single dose of epidural ketamine injection to minimize preservative amounts and exposure duration at spinal cord. In our case, we choose a lower single dose of epidural ketamine, and it produced sufficient analgesia without adverse effect. The analgesic effect may be related to blocking of nociceptive input and central sensitization at acute stage of herpetic neuralgia. Further research is needed to evaluate the long-term outcomes, particularly the exclusion of potential neurotoxicity.

In conclusion, a single epidural injection of ketamine produces analgesia for intractable herpetic neuralgia. Further study, including large clinical trials, will be needed to clarify the neurotoxicity and margin of safety for epidural ketamine dosage.

\section{References}

1. Koinig H, Marhofer P, Krenn CG, Klimscha W, Wildling E, Erlacher W, et al. Analgesic effects of caudal and intramuscular S(+)-ketamine in children. Anesthesiology 2000; 93: 976-80.

2. Martindale SJ, Dix P, Stoddart PA. Double-blind randomized controlled trial of caudal versus intravenous S(+)-ketamine for supplementation of caudal analgesia in children. Br J Anaesth 2004; 92: 344-7.

3. Xie H, Wang X, Liu G, Wang G. Analgesic effects and pharmacokinetics of a low dose of ketamine preoperatively administered epidurally or intravenously. Clin J Pain 2003; 19: 317-22.

4. Schnabel A, Poepping DM, Kranke P, Zahn PK, Pogatzki-Zahn EM. Efficacy and adverse effects of ketamine as an additive for paediatric caudal anaesthesia: a quantitative systematic review of randomized clinical trials. Br J Anaesth 2011; 107: 601-11.

5. Ansermino M, Basu R, Vandebeek C, Montgomery C. Nonopioid additives to local anaesthetics for caudal blockade in children: a systemic review. Paediatr Anaesth 2003; 13: 561-73.

6. Wood MJ, Kay R, Dworkin RH, Soong SJ, Whitley RJ. Oral acyclovir therapy accelerates pain resolution in patients with herpes zoster: a meta-analysis of placebo-controlled trials. Clin Infect Dis 1996; 22: 341-7.

7. Koc Y, Miller KB, Schenkein DP, Griffith J, Akhtar M, DesJardin J, et al. Varicella zoster virus infections following allogeneic bone marrow transplantation. Biol Blood Marrow Transplant 2006; 6: 44-9.

8. Jung BF, Johnson RW, Griffin DR, Dworkin RH. Risk factors for postherpetic neuralgia in patients with herpes zoster. Neurology 2004; 62: 1545-51.

9. Hirota K, Lambert DG. Ketamine: its mechanism(s) of action and unusual clinical uses. Br J Anaesth 1996; 77: 441-4.

10. Laulin JP, Maurette P, Corcuff JB, Rivat C, Chauvin M, Simonnet G. The role of ketamine in preventing fentanyl-induced hyperalgesia and subsequent acute morphine tolerance. Anesth Analg 2002; 94: 1263-9.

11. Walker SM, Westin BD, Beumens R, Grafe M, Yaksh TL. Effects of intrathecal ketamine in the neonatal rat: evaluation of apoptosis and long-term functional outcome. Anesthesiology 2010; 113: 147-59.

12. Vranken JH, Troost D, de Haan P, Pennings FA, van der Vegt MH, Dijkgraaf MG, et al. Severe toxic damage to the rabbit spinal cord after intrathecal administration of preservative-free S(+)-ketamine. Anesthesiology 2006; 105: 813-8.

13. Malinovsky JM, Lepage JY, Cozian A, Mussini JM, Pinaudt M, Souron R. Is ketamine or its preservative responsible for neurotoxicity in the rabbit? Anesthesiology 1993; 78: 109-15.

14. Karpinski N, Dunn J, Hansen L, Masliah E. Subpial vacuolar myelopathy after intrathecal ketamine: report of a case. Pain 1997; 73: 103-5. 